\title{
Combinations of School-Based Primary and Secondary Preventive Dental Programs in the United States and Other Countries
}

\author{
Robert A. Bagramian, DDS, DrPH*
}

To report on the success of school-based dental programs has proved to be a somewhat difficult task for two reasons: first, there are few such programs within the United States; and, second, United States school based primary and secondary preventive dental programs are fragmented, not comprehensive nor continuous and rarely reported in the literature.1.2.3 For this presentation, primary prevention is defined as those efforts directed toward preventing a disease or condition prior to its occurrence while secondary prevention refers to those efforts to treat or control a disease once it has occurred. Further, secondary prevention includes early diagnosis, prompt treatment, and limitation of disability. There has been little comprehensive programming in this area with the result that much of the evidence for success of these programs comes primarily from countries other than the United States. Philosophical differences may account for this discrepancy as most provisions for dental services for children in the United States occur within the private practice system; a system not available to the entire population for a host of reasons wellknown to public health professionals. It has been demonstrated in other countries that well-managed school-based dental programs can provide quality care in a setting that is conducive to a minimum of disruptions, as well as demonstrating significantly reduced capital and operating expenses. The overwhelming majority of school-based dental programs in the United States relate to primary prevention, again probably related to the posture of the profession, and that is to provide dental treatment in private dental offices. Most school-based programs in the United States deal with brushing, application of topical fluorides, and oral screening.

\section{Secondary Prevention}

There is an obvious absence of secondary prevention in the school systems of the United States. On an international basis, numerous countries have established school-based dental programs for all children. New Zealand has had a program for over 50 years in which dental nurses trained for two years provide direct care to children in schools. The New Zealand dental nurse program has been reviewed many times over the years with positive conclusions.3.4.5 Other countries with school-based dental programs are Norway, Denmark, and Sweden.6.7 In addition, programs also utilizing dental nurse practitioners have recently begun in Australia ${ }^{8}$ and Saskatchewan, Canada. 9 Other countries that are developing such programs are Sri Lanka, Great Britain, Indonesia, Malaysia, Singapore, and Thailand. (1) Most of the programs presently being developed in the United States deal only with primary prevention. Programs which involve any form of secondary prevention such as early diagnosis and treatment for lesions are usually only available for specific groups such as the economically disadvantaged. These programs almost invariably are not school-based but rather located at health departments or in private offices. 11.12 The

*Professor and Chairman, Department of Community Dentistry, School of Dentistry, The University of Michigan, Ann Arbor, MI 48109. 
Indian Health Service school-based programs are for a limited segement of the population on Indian Reservations. ${ }^{11.14}$

The basic questions are these: Can school-based dental programs be successful? In the sense of participation, will children attend and will parents allow their youngsters to be treated? Can the quality be safeguarded and maintained? Can costs be competitive--does it cost more to treat children in school settings or in private dental offices? Is the program cost effective? And most important, can school-based preventive programs reduce and control dental disease?

Several of these questions have been answered in the literature. School-based programs do result in high utilization rates. New Zealand reports 60 percent of all preschool children and 95 percent of school children between $2 \frac{1}{2}$ and 13 receive routine dental care from dental nurses in clinics located at schools. ${ }^{4}$ Norway which has had a school-based dental service utilizing salaried dentists since 1910 reported that Oslo had 92 percent of parents of school children requesting care. ${ }^{15}$ The United States has not fared so well. ${ }^{16}$

Up to this point, the measures that can be used to assess success of school-based programs - participation and acceptance, cost effectiveness, and dental benefits--have been examined. Few programs have been conducted to study these parameters in the United States. Two experimental studies have been reported. One experimental program has been providing incremental dental care at no charge to eligible children in a 13-county bistate region through three delivery systems (private dentists in their offices, salaried dentists in fixed public clinics, and salaried dentists in mobile units). ${ }^{17}$ Cost effectiveness studies of these systems have shown that schoolbased care via mobile units costs less than busing children to private offices.17.18

The other study funded by the National Institute for Dental Research, was a five-year prevention program. The stated purpose was to demonstrate that a combination of effective prevention regimens could significantly reduce dental caries for a selected group of 600 school children. This school-based project was conducted by The University of Michigan in a fluoridated community. The procedures utilized were:

(1) Oral hygiene instructions including brushing and flossing during the school year; this was integrated into the school curriculum and included instructions on diet and nutrition and good dental health;

(2) Biannual applications of 1.24 percent acidulated phosphate fluoride gel in mouthguards;

(3) Application of Bis-GMA sealants to all available occlusal surfaces; and

(4) Provision of all necessary routine restorative procedures on a regular basis.

In addition, all children received a complete oral examination including bitewing $\mathrm{x}$-rays. Approximately 600 additional children served as a comparison group and received the annual examinations and participated in the oral hygiene program. A description of the program and early results have been previously published. ${ }^{19-22}$ In evaluating this program the previously stated criteria may be used:

(1) Participation: 85 percent of students in the first and sixth grades volunteered; 51 percent of the students were still active participants five years later.

(2) Cost: Although the purpose of this project was not to evaluate costs, the total cost per student per year was $\$ 146.58$. (The initial cost of $\$ 75,000$ for two mobile vans was not amortized.) 
(3) Dental benefits: In addition to the clinical procedures already described briefly, the children in the treatment group as well as those in the control group (along with nonparticipating children) received oral hygiene instruction in the classroom as a part of their daily routine, in the first year of the project, using the "Toothkeeper Program." In consultation with the school system health staff, a decision was made to hire a full time dental health educator (hygienist with a degree in education) to coordinate and supervise this educational aspect of the study, in place of the "Toothkeeper Program." Also, each year inservice workshops were conducted for the appropriate teachers. Supervision of the oral hygiene activities was implemented on a routine basis with the result that at the end of the project, oral hygiene instruction was integrated as an ongoing part of the health curriculum.

By the end of the five-year period, there were three groups of children to compare: Treatment Group 1 which had received full services for five years; Treatment Group 2 which had received full services for three years; and the comparison group which had not received treatment during the study, but only annual examinations and oral hygiene instruction in their classes.

Results

At the end of four years, the percent reduction in caries increment for Treatment Group 1 of original first and sixth graders was 58 percent and 77 percent respectively. Corresponding figures for Treatment Group 2 of original first and sixth graders was 45 percent and 51 percent respectively. The complete findings may be found in the Journal of the American Dental Association. ${ }^{22}$ These results are impressive considering that water fluoridation had already reduced the level of caries significantly for all these children. It can be stated that for Treatment Group 1, dental caries had been essentially prevented.

\section{Summary}

School-based programs in the United States are very limited. Other countries in the world have established programs for many years which provide comprehensive services to school-age children. In this country philosophical and professional pressures have maintained school-based programs only in the area of primary prevention. Most treatment programs involving secondary prevention are not school-based and are targeted at specific population groups rather than all children. The basic questions of whether primary and secondary preventive school-based programs can be successful have been examined in this paper. The evidence based on the pilot program presented here is that these programs can be successful. They are well accepted by parents and children, they provide quality care at a reasonable cost, and, most importantly, they can reduce dental disease. It's time for a commitment by the profession and the nation to establish school-based dental programs for the health and welfare of our children.

\section{References}

1. Dunning, J. M. A word of warning in incremental dental care, N. Y. J. Dent. 38:56-9, Feb. 1968.

2. Cons, N. C. Dental care under Head Start. J. Pub. Health Dent. 27:121-2, Summer, 1967.

3. Dunning, J. M. Principles of dental public health and ed. Cambridge, Harvard University Press. 1970. p. XIV + 598 p.

4. Friedman, J. W. The New Zealand school dental service: lesson in radical conservatism. Am. Dent. A. J. 85:609-17, Sept. 1972. 
5. Redig, D., Dewhirst, F., Nevitt, G. et al. Delivery of dental services in New Zealand and California. South. Calif. Dent. A. J. 41:318-50, Apr. 1973.

6. Cohen, L. K. How the study was designed. Int. Dent. J. 26:293-8, Sept. 1976.

7. Bawden, A. W. Dental care in Sweden, N. C. Dent. J. 59:19-21, Spring, 1976.

8. Dunning, J. M. Deployment and control of dental auxiliaries in New Zealand and Australia. Am. Dent. A. J. 85:618-26, Sept. 1972.

9. Lewis, M. H. The Saskatchewan dental plan: a dental nurse program after two years in operation. Am. Pub. Health A. Abstr. Ann. Meet., Abstr. no. 4044, n.v. 193, 1976.

10. Roemer, Ruth. The legal scope of dental hygienists in the United States and other countries. Pub. Health Rep. 85:941-8, Nov. 1970.

11. Bishop, E. M., and Christensen, H. M. Dentists and the war on poverty: a discussion of neighborhood health centers. Am. Dent. A. J. 75:45-54, July 1967.

12. Dunning, J. M. Dental care for everyone. Cambridge, Harvard University Press, 1976. (pp. 85-7.)

13. Abramowitz, J. A children's dental program for American Indians. Amer. Dent. A. J., 81:395-405, Aug. 1970.

14. Jenny, J., et al. Measuring dental health status to assess quality in dental care delivery systems. Abstr. J. Dent. Res., 56:B93, June 1977.

15. Sebelius, C. L. Trends in preventive dentistry in the United States and Scandanavia. Am. Col. Dent. J. 19:313-20, Sept. 1952.

16. National Health Survey. Dental Visits, Volume and Interval since Last Visit, United States, 1969 DHEW Publication No. (HSM) 72-1066, Series 10, No. 76.

17. Doherty, N., and Vivian, S. L. Expenditures for the dental care of indigent children in the Chattanooga project, 1971-1975. J. Pub. Health Dent., 37: 209-16 Summer 1977.

18. Doherty, N., and Vivian, S. L. Costs of publicly financed dental care for children in three different types of practice settings. J. Pub. Health Dent. 36:3-8, Winter 1976.

19. Bagramian, R. A., Graves, R. C., and Bhat, M. A combined approach to preventing dental caries in school children: caries reductions after one year. Am. Dent. A. J., 93:1014-9, Nov. 1976.

20. Bagramian, R. A., Graves, R. C., and Srivastava, S. Sealant effectiveness for children receiving a combination of preventive methods in a fluoridated community: Two year results. J. Dent. Res. 56:1511-19.

21. A combined approach to preventing dental caries in school children: caries reduction after 3 years. Community Dent. Oral Epidemiol., 6:166-71, July 1978.

22. S. Pattern of sealant retention in children receiving a combination of preventive methods -3 year results. Am. Dent. A. J., 98:46-50, Jan. 1979.

The end of training is to learn something specific, but the end of education is to learn how to learn. Without this, all training is futile, for the knowledge and aptitudes needed in one decade become nearly obsolete in the next.

-Sidney Harris in the Detroit Free Press for July 27, 1979 